\title{
UM ESTUDO EXPLORATÓRIO SOBRE A INSERÇÃO DA NATUREZA DA CIÊNCIA NA SALA DE AULA EM REVISTAS DA ÁREA DE ENSINO DE CIÊNCIAS
}

\author{
B. V. C. SILVA* , E. C. SOUSA, L. A. NASCIMENTO e H. R. CARVALHO \\ Universidade Federal do Piauí \\ boniek@ufpi.edu.br*
}

Artigo submetido em junho/2015 e aceito em setembro/2016

DOI: $10.15628 /$ holos.2016.3138

\section{RESUMO}

No Brasil, a partir dos anos 80, estudos apresentados a respeito do tema Natureza da Ciência ( $\mathrm{NdC}$ ) têm mostrado a visão empírica que recaí sobre tais conteúdos que podem ser aplicados em sala de aula. O trabalho apresenta uma análise qualitativa e quantitativa feita em revistas da área de Ensino de Ciência. Ele teve o objetivo de analisar as metodologias utilizadas para a inserção do tema Natureza da Ciência nelas. Neste sentido, foi feita uma triagem de artigos em quatro (4) revistas, sendo (3) nacionais e (1) internacional, que publicam artigos nesta direção. Nesta triagem encontramos 719 trabalhos que apresentam o termo Natureza da Ciência em seus resumos. Destes, somente 15 artigos passaram por uma análise, a qual tinha por objetivo incluí-los ou não no estudo. Como resultados, podemos notar que a maioria das intervenções didáticas sobre a $\mathrm{NdC}$ se dão na formação de professores, com destaque aos cursos de Física. Outro ponto relevante é a tentativa de inserção desta temática no ensino médio. Entretanto, um dado que chama a atenção, de forma negativa, é a falta de intervenções sobre a $\mathrm{NdC}$ no ensino fundamental, o que denota um possível campo de estudos futuros.

PALAVRAS-CHAVE: Ensino de Ciências, Natureza da Ciência, Revistas, Sala de Aula.

\section{UN ESTUDIO EXPLORATORIO SOBRE LA INCLUSIÓN DE LA NATURALEZA DE LA CIENCIA EN EL CLASE EN REVISTAS DE ENSEÑANZA DE LAS CIENCIAS}

\section{RESUMEN}

En Brasil, a partir de los años 80 estudios que se presentan en la naturaleza objeto de la Ciencia ( $\mathrm{NdC}$ ) han mostrado la vista empírico que recayó sobre tales contenidos que se pueden aplicar en el aula. El artículo presenta un análisis cualitativo y cuantitativo en el área de la enseñanza revistas Ciencia. Su objetivo era analizar los métodos utilizados para emitir la inclusión de la Naturaleza Ciencias ellos. En este sentido, una de cada cuatro artículos de cribado se realizó revistas (4), (3) nacional (1) internacional, que publican artículos en esta dirección. Esta evaluaciónencontró 719 puestos de trabajo que tiene la naturaleza término de la Ciencia en sus hojas de vida. De éstos, sólo 15 artículos han sido objeto de unanálisis, cuyo objetivo era incluirlos o no enelestudio. Como resultado, se observa que la mayoría de las intervenciones educativas em $\mathrm{NdC}$ se danen la formación Del profesorado, conénfasis em los cursos de física. Outro punto relevante es el intento de introducir este tema en la escuela secundaria. Sin embargo, um hecho que llama la atención de una manera negativa, es la falta de intervenciónen el $\mathrm{NdC}$ en la escuela primaria, lo que denota unposible campo de los estudios futuros.

KEYWORDS: Educación Ciencia, Naturaleza de la Ciencia, Revistas, Aula. 


\section{INTRODUÇÃO:}

O termo Natureza da Ciência ( $\mathrm{NdC}$ ) vem sendo usado em pesquisas e trabalhos científicos, como podemos nos certificar por meio de investigação de estudos publicados no Brasil, em especial a partir dos anos 80 (ATAÍDE; SILVA, 2011).

A Ciência, como também todos os componentes que a influência para o seu desenvolvimento, conta hoje com várias pesquisas realizadas durante todos esses anos em apresentações de trabalhos, publicações em revistas e pesquisas por todo o país e fora dele, mostrando que há um consenso sobre a inserção desta temática no Ensino de Ciência.

As observações apresentadas acima são possíveis graças às revisões sistemáticas das publicações que abordam os mais variados temas destinados à $\mathrm{NdC}$ no Brasil e em outros países (SILVA, 2010). Para Teixeira, Greca e Freire (2012), a revisão sistemática de literatura, é um dos métodos mais eficazes para se fazer críticas sintéticas e obter resultados seguros de uma grande quantidade de publicações sobre um tema de uma determinada área do conhecimento.

Geralmente, os autores deste tipo de pesquisa, após uma ampla varredura nas fontes de publicações (geralmente periódicos e órgãos de fomento à pesquisa) elaboram critérios excludentes para os trabalhos que estão fora dos objetivos pretendidos para elaboração da pesquisa, ao mesmo tempo em que selecionam para análise os que estão de acordo com os objetivos (TEIXEIRA; GRECA; FREIRE, 2012).

Ao realizar uma revisão sistemática de um determinado tema de uma determinada área do conhecimento, os resultados desta pesquisa caracterizam o chamado "Estado da Arte" ou "Estado do Conhecimento" das pesquisas que abordam aquele determinado tema daquela determinada área do conhecimento.

Retornando aos estudos sobre o Ensino de Ciência, pode-se indicar para uma revisão sistemática, dentre os variados temas de pesquisas sobre Ensino de Ciência, o tema Natureza da Ciência na sala de aula. De acordo com Silva (2010), o tema "Natureza da Ciência a sua aplicação" se torna difícil por se dar a respeito do conhecimento epistemológico de cada individuo sobre o tema, o implica a necessidade de estudos mais aprofundados sobre Epistemologia da Ciência.

Contudo, como ressalta Silva (2014a), em seus estudos, nos cursos de formação de professores de ciências, de forma geral, existem poucos espaços para a discussão tanto de aspectos Históricos e Filosóficos das Ciências como a sua inserção na sala de aula.

Segundo Silva et al (2014b), mesmo com a disciplina nos cursos de formação, para se inserir a NdC, principalmente por intermédio da História e Filosofia da Ciência (HFC), o professor precisa de necessidades formativas, algumas (por exemplo: conhecimentos de Historiografia da Ciência, Didática das Ciências e Epistemologia das Ciências) que não são discutidas na sua formação. Este fato pode potencializar dificuldades na sua inserção, ou até mesmo, propostas de intervenções didáticas inadequadas.

Baseando-se nessa temática, no presente trabalho apresentamos o "Estado da Arte" das pesquisas que investigam intervenções didáticas em salas de aula no Ensino de Ciência, tendo como eixo condutor a $\mathrm{NdC}$, e que estão publicadas em algumas revistas brasileiras e internacional especializadas. 


\subsection{Natureza da Ciência e Ensino de Ciências:}

Nas últimas décadas, a $\mathrm{NdC}$ vem ganhando um papel de destaque nas reformulações dos currículos de ciências em vários países pelo mundo (ACEVEDO, 2008; 2009; LEDERMAN, 1999). Alguns trabalhos (Lederman, 1999; Acevedo, 2008; Acevedo et al, 2007a; 2007b; Pagliarini, 2007; Briccia; Carvalho, 2011) indicam que a NdC figura, atualmente, como um dos objetivos fundamentais para uma melhora da alfabetização científica.

Durante a década de noventa do século passado, Segundo Acevedo (2008), a NdC começou a ser destacada como uma espécie de objetivo chave no currículo de ciências escolar e, além disso, passou a ser considerada também uma componente fundamental da alfabetização científica.

Convergimos com o que os autores da área definem a respeito do conceito de $\mathrm{NdC}$ (vejamos alguns exemplos: MOURA, 2008 e FORATO, 2009), suas definições se baseiam em princípios epistemológicos, envolvidos na construção do conhecimento científico, que incorporam, entre outras coisas, as crenças e valores intrínsecos da Ciência, seus objetivos, metodologias de pesquisa e os processos de aceitação ou rejeição das ideias científicas.

Dessa forma, "pode-se afirmar que a Natureza da Ciência ( $\mathrm{NdC}$ ) pode ser entendida como a união de conhecimentos sobre a ciência que discute sobre seus objetivos, as influências sofridas e/ou causadas sobre a sociedade da época, suas limitações, seu pluralismo metodológico, a aceitação ou rejeição de ideias científicas, dos equívocos cometidos pelos cientistas, o seu caráter provisório, dentre outros temas." (CARVALHO, 2015, p.41)

Não obstante, apesar da existência de visões distintas acerca da definição de $\mathrm{NdC}$, um certo acordo parece já existir na atualidade entre os especialistas em didática das ciências e a comunidade internacional de cientistas sobre um significado da $\mathrm{NdC}$ útil para o ensino de ciências (ACEVEDO, 2008).

Segundo Acevedo (2008), os professores além de ensinarem de maneira consistentes os atuais pontos de vista sobre a ciência, devem também se engajar em ensinar aos estudantes determinados aspectos relacionados à $\mathrm{NdC}$.

No entanto, como alertam alguns autores [Acevedo (2008); Carvalho (2015)], apesar de já haver, de certa forma, um consenso em relação à importância da NdC como um fator para a melhoria da forma como a educação científica dos cidadãos vem sendo feita, não é difícil perceber que o ensino de ciências vem fracassando, até agora, para alcançar esse objetivo.

Esse fracasso, na visão de Carvalho (2015), tem relação, por exemplo, com a falta de preparo dos professores para discutir assuntos relacionados à $\mathrm{NdC}$ na sala de aula; a falta de discussões ainda no processo de formação de professores ou até por não haver uma cobrança sobre esse tema em vestibulares, dentre outros.

Para que seja possível se adentrar um pouco mais nas discussões a respeito da relação da $\mathrm{NdC}$ com o ensino de ciências é importante que tenhamos em mente o porquê da importância da NdC para o currículo de ciências.

Para isso, iremos nos basear em razões sucintas, para a inserção da $\mathrm{NdC}$ no currículo de ciências, encontradas nos trabalhos de Acevedo (2008) e Lederman (2007). Os autores apontam cinco razões pelas quais se consegue perceber o quão importante pode ser a $\mathrm{NdC}$ para o ensino de Ciências, a saber: Utilitária, Democrática, Cultural, Axiológica e Docente (Quadro 1).

Quadro 1: Razões apontadas por Driver et al (1996) apud Acevedo (2008) e Lederman (2007) pelas quais se faz importante a inserção da NdC no currículo de ciências. 
$\checkmark$ Utilitária: O entendimento da NdC é necessário para se ter uma ideia correta da ciência e gerenciar os objetos e processos tecnológicos na vida cotidiana.

$\checkmark$ Democrática: Compreender a $\mathrm{NdC}$ é necessário para que se tome decisões mais informadas acerca de questões tecnocientíficas com interesse social.

$\checkmark$ Cultural: A compreensão da NdC é necessária para se apreciar o valor da ciência como um elemento importante da cultura contemporânea.

$\checkmark$ Axiológica: A compreensão da NdC ajuda a entender melhor as normas e valores da comunidade científica que contém compromissos éticos com um valor geral para a sociedade.

$\checkmark$ Docente: Entendimento da NdC facilita a aprendizagem dos conteúdos das matérias científicas e, por conseguinte, uma mudança conceitual.

Ainda nesse sentido, Ferreira e Martins (2012), apontam que há uma sugestão que os conhecimentos sobre $\mathrm{NdC}$ seriam relevantes para a tomada de decisões conscientes pela sociedade. Além disso, os autores concordam com os motivos, citados no Quadro 2, pelos quais seria importante a utilização da $\mathrm{NdC}$ no ensino, pois afirmam que

\footnotetext{
Outros argumentos são citados na literatura a favor da pertinência desse tema para o ensino: manipulação e entendimento da tecnologia; compreensão das normas da comunidade científica; sucesso no aprendizado de conteúdos da ciência; satisfação dos estudantes ao aprender sobre NdC. (FERREIRA; MARTINS, 2012, p.156)
}

Dentre os argumentos apontados no Quadro 2, um em especial é normalmente indicado para se incluir a NdC no currículo de ciências escolar, qual seja, o democrático, ou seja, a partir de um conhecimento adequado da Natureza da Ciência ( $N d C)$, nesse sentido, facilitaria

[...] a realização de melhores análises das questões tecnocientíficas controversas com interesses pessoal e social e informar-se melhor sobre os assuntos que se abordam nessas questões, assim como contribuir para uma melhora das características e a qualidade das decisões que são tomadas a respeito. (ACEVEDO, 2008, p.141)

Outro argumento que é bastante citado quando se tenta defender a relevância da NdC nos currículos de ciências é o docente, segundo o qual "uma melhor compreensão da NdC pelos estudantes lhes permitirá melhorar seu rendimento na aprendizagem dos demais conteúdos científicos e facilitar, assim, uma evolução conceitual progressiva" (ACEVEDO, 2008, p.142).

No próximo tópico, iremos apresentar os objetivos, aspectos metodológicos da pesquisa e os instrumentos utilizados no estudo.

\section{DESENHO DO ESTUDO: OBJETIVOS, METODOLOGIA E INSTRUMENTOS UTILIZADOS:}

O propósito da pesquisa foi realizar uma revisão sistemática de revistas da área de Ensino de Ciência que, em seu corpo, publicam artigos que tem por objetivo apresentar manuscritos que apresentam trabalhos que relatam a inserção da $\mathrm{NdC}$ na sala de aula. 
A investigação se vale de uma abordagem qualitativa e quantitativa, como caracterizada por Marconi (2003) e Moreira (2011). Utilizamos a técnica de análise de conteúdo de Laurence Bardin para categorizarmos nossos dados e análise documental, que segundo Bardin (2009), permite:

[...] o desenvolvimento de um instrumento de análise de comunicações seguindo passo a passo o crescimento quantitativo e a diversificação qualitativa dos estudos empíricos apoiados na utilização de uma das técnicas classificadas sob a designação genérica de análise de conteúdo; é observar a posteriori os aperfeiçoamentos materiais e as aplicações abusivas de uma pratica que funciona há mais de meio século (BARDIN, 2009, p.15).

Dessa forma, a busca pelos trabalhos, que se enquadram nesta linha, foi feita de forma cuidadosa, número a número, separando os trabalhos por palavra-chave e resumo. Para uma compreensão maior sobre o resumo, foi feita uma leitura minuciosa dos mesmos. Todos os trabalhos que se encaixavam no nosso objetivo "o uso de trabalhos que retrata a importância da $\mathrm{NdC}$ na sala de aula" foram, previamente, selecionados.

Para o processo metodológico de seleção dos trabalhos para análise, selecionamos 4 revistas: três revistas brasileiras e uma espanhola. Utilizamos como critério destas revistas, o fato de seus trabalhos serem publicados no Brasil e por incluir, no seu corpo, trabalhos que retratam a $\mathrm{NdC}$ na sala de aula. São elas:

- $\quad$ Revista Experiências em Ensino de Ciência (EENCI) ${ }^{1}$;

- $\quad$ Revista Electrónica de Enseñanza de las Ciencias (REEC);

- $\quad$ Revista Química Nova na Escola (QNEsc) ${ }^{3}$ e

- Revista Investigações em Ensino de Ciências (IENCI) ${ }^{4}$.

Após a seleção das revistas, criamos critérios para inclusão dos artigos para uma leitura posterior. São eles:

I. Artigos que tratam das concepções de ciências alunos de cursos superiores (TCES).

II. Artigos que tratam das concepções de ciências de alunos da educação básica (TCEB).

III. Artigos de natureza teórica, incluído a reflexão didática sobre aspectos da $\mathrm{NdC}$ (TRNDC).

IV. Artigos sobre o uso de aspectos Históricos da Ciência voltados para a educação básica (THCEB).

V. Artigos sobre o uso de aspectos Históricos da Ciência voltados para o ensino superior (THCES).

VI. Artigos voltados para a formação de professores e a NdC (TFP).

VII. Artigos com discussão em espaços não formais de ensino e a $\mathrm{NdC}$ (TEFN).

Escolhemos o período de 2004 a 2013, pois a revista EENCI teve seu primeiro número publicado em 2006. Do total de trabalhos que apresentavam palavras-chave relacionadas com a

\footnotetext{
${ }^{1}$ http://if.ufmt.br/eenci/

${ }^{2}$ http://reec.uvigo.es/

${ }^{3}$ http://qnesc.sbq.org.br/

${ }^{4}$ http://www.if.ufrgs.br/ienci/?go=home
} 
NdC, encontramos 719 manuscritos. Após serem submetidos aos nossos critérios de inclusão, foram selecionados 15 trabalhos que estavam diretamente relacionados com as publicações existentes sobre o uso da NdC em diferentes áreas no Ensino de Ciência.

Os trabalhos foram publicados entre 2004 a 2013 (quando foi concluída a coleta das fontes para estudo das publicações sobre uso da $\mathrm{NdC}$ em diferentes concepções de ensino). Em seguida no quadro 2 é apresentado a classificação dos resultados contendo o número de artigos encontrados por ano e por revista.

Quadro 2: números de artigos publicados por ano.

\begin{tabular}{|c|c|c|c|c|c|}
\hline \multirow{2}{*}{ Ano } & \multirow{2}{*}{$\begin{array}{l}\text { Números de } \\
\text { artigos por ano }\end{array}$} & \multicolumn{4}{|c|}{ Números de artigo por revista } \\
\hline & & EENCI & IENCI & REEC & QNESq \\
\hline 2004 & 1 & & 1 & & \\
\hline \multicolumn{6}{|l|}{$2005^{*}$} \\
\hline 2006 & 1 & & & 1 & \\
\hline 2007 & 1 & & 1 & & \\
\hline 2008 & 1 & & & & 1 \\
\hline 2009 & 2 & & 1 & 1 & \\
\hline 2010 & 3 & 2 & 1 & & \\
\hline 2011 & 2 & & 1 & 1 & \\
\hline 2012 & 2 & 1 & & 1 & \\
\hline 2013 & 2 & & & 2 & \\
\hline Total & 15 & 3 & 5 & 6 & 1 \\
\hline
\end{tabular}

*Neste ano e nas revistas selecionadas, não foram encontrados trabalhos que apresentavam palavras-chave relacionadas com a $\mathrm{NdC}$.

Fonte: Elaborado pelos autores

Apresentamos abaixo os quadros 3, 4, 5 e 6, os quais apresentam os artigos selecionados em cada revista. Vale destacar que cada quadro corresponde a um tipo de revista selecionada para análise.

Quadro 3: Artigos selecionados da revista IENCI para análise.

\begin{tabular}{|c|c|c|c|}
\hline Trabalho & Ano & Autores & Título \\
\hline 1 & 2004 & $\begin{array}{l}\text { EL-HANI, C. N.; } \\
\text { TAVARES, E. J. M.; } \\
\text { ROCHA, P. L. B } \\
\end{array}$ & $\begin{array}{c}\text { Concepções epistemológicas de estudantes de Biologia e sua } \\
\text { transformação por uma proposta explicita de ensino sobre } \\
\text { História. }\end{array}$ \\
\hline 2 & 2007 & $\begin{array}{l}\text { SCHEID, N. M. J.; } \\
\text { FERRARI, N.; } \\
\text { DELIZOICOV, D. }\end{array}$ & $\begin{array}{c}\text { Concepções sobre a Natureza da Ciência num curso de biológicas: } \\
\text { imagens que dificultam a Educação científica. }\end{array}$ \\
\hline 3 & 2009 & $\begin{array}{l}\text { CHINELLI, M. V.; } \\
\text { AGUIAR, L. E. V. }\end{array}$ & $\begin{array}{l}\text { Experimentos e contextos nas exposições interativas dos centros e } \\
\text { museus de ciências. }\end{array}$ \\
\hline 4 & 2010 & $\begin{array}{l}\text { PAULA, H. F.; LIMA, } \\
\text { M. E. C. C. }\end{array}$ & Formulação de questões mediação da Leitura \\
\hline 5 & 2011 & $\begin{array}{l}\text { ALMEIDA, A. V.; } \\
\text { FARIAS., C. R. O }\end{array}$ & $\begin{array}{l}\text { A Natureza da Ciência na formação de professores: reflexões a } \\
\text { partir de um curso de licenciatura em ciência biológicas. }\end{array}$ \\
\hline
\end{tabular}

Fonte: Elaborado pelos autores.

Quadro 4: Artigos selecionados da revista QNESC para análise.

\begin{tabular}{|c|c|c|r|}
\hline Trabalho & Ano & Autores & Título \\
\hline
\end{tabular}




\begin{tabular}{|c|c|c|c|}
\hline 6 & 2007 & VÁZQUES-ALONSO, A. et al. & $\begin{array}{c}\text { Consensos sobre a Natureza da Ciência: A Ciência e a } \\
\text { Tecnologia na Sociedade. }\end{array}$ \\
\hline
\end{tabular}

Fonte: Elaborado pelos autores.

Quadro 5: Artigos selecionados da revista REEC para análise.

\begin{tabular}{|c|c|c|c|}
\hline Trabalho & Ano & Autores & Título \\
\hline 7 & 2007 & $\begin{array}{l}\text { REIS P.; } \\
\text { GALVÃO C. }\end{array}$ & $\begin{array}{l}\text { O diagnóstico de concepções sobre os cientistas através da } \\
\text { análise e discussão de histórias de ficção regidas pelos alunos. }\end{array}$ \\
\hline 8 & 2009 & $\begin{array}{l}\text { REIS P.; } \\
\text { GALVÃO C.; }\end{array}$ & $\begin{array}{l}\text { Os professores de Ciências Naturais e as discussões de } \\
\text { controvérsias sócio científicas: dois casos distintos. }\end{array}$ \\
\hline 9 & 2011 & TOBALDINI, B. G. et al. & $\begin{array}{l}\text { Aspectos sobre a Natureza da Ciência por alunos e professores } \\
\text { de licenciatura em ciências biológicas. }\end{array}$ \\
\hline 10 & 2012 & $\begin{array}{l}\text { LONGHI, A.; } \\
\text { SCHROEDER, E. }\end{array}$ & $\begin{array}{l}\text { Clubes de ciências: o que pensam os professores } \\
\text { coordenadores sobre ciência, natureza da ciência e iniciação } \\
\text { científica numa rede municipal de ensino. }\end{array}$ \\
\hline 11 & 2013 & $\begin{array}{l}\text { OLEQUES, L. C.; BOER, } \\
\text { N.; LADVOCAT, M. }\end{array}$ & $\begin{array}{c}\text { Reflexões acerca das diferentes visões sobre a natureza da } \\
\text { ciência e crenças de alunos de um curso de Ciências } \\
\text { Biológicas. }\end{array}$ \\
\hline 12 & 2013 & $\begin{array}{l}\text { HYGINO, C. B.; SOUZA, } \\
\text { N. S.; LINHARES, M. P. }\end{array}$ & $\begin{array}{l}\text { Episódios da história da ciência em aulas de física com alunos } \\
\text { jovens e adultos: uma Proposta didática articulada ao método } \\
\text { de estudo de caso. }\end{array}$ \\
\hline
\end{tabular}

Fonte: Elaborado pelos autores.

Quadro 6: Artigos selecionados da revista EENCI para análise.

\begin{tabular}{|c|c|c|c|}
\hline Trabalho & Ano & Autores & Título \\
\hline 13 & 2010 & SILVEIRA, A. F. et al & $\begin{array}{r}\text { Natureza da Ciência numa sequencia didática: Aristóteles, } \\
\text { Galileu e o movimento relativo. }\end{array}$ \\
\hline 14 & 2010 & $\begin{array}{r}\text { SILVA, B. V.C. } \\
\text { MARTINS, A. F. P. }\end{array}$ & $\begin{array}{r}\text { Natureza da luz e o ensino da óptica: Uma experiência didática } \\
\text { envolvendo o uso da historia e da filosofia do ensino médio. }\end{array}$ \\
\hline 15 & 2012 & $\begin{array}{r}\text { HYGINO, C. B.; SOUZA, } \\
\text { N. S.; LINHARES, M. P.. }\end{array}$ & $\begin{array}{r}\text { Reflexões sobre a Natureza da Ciência em aulas de física: } \\
\text { estudo de um episódio histórico no Brasil colonial. }\end{array}$ \\
\hline
\end{tabular}

Fonte: Elaborado pelos autores.

No próximo tópico, faremos a análise dos artigos selecionados, tomando como base os critérios de inclusão descritos.

\section{UMA PESQUISA SOBRE A NATUREZA DA CIÊNCIA NA SALA DE AULA ANALISANDO OS RESULTADOS:}

Iniciaremos nossa análise de forma quantitativa, onde apresentaremos nossos resultados por intermédio de quadros. O quadro 7 apresenta a quantidade de artigos produzidos entre 2004 e 2013 e sua respectiva revista. Utilizaremos os respectivos códigos para os periódicos: $R_{1}(I E N C I), R_{2}(Q N E S C)$, $\mathrm{R}_{3}(\mathrm{REEC}), \mathrm{R}_{4}(\mathrm{EENCl})$. 
Quadro 7: Quantidade de artigos por revista.

\begin{tabular}{|c|c|}
\hline Revista & No de artigos \\
\hline $\mathrm{R}_{1}$ (IENCI) & 05 artigos \\
\hline $\mathrm{R}_{2}$ (QNESC) & 01 artigo \\
\hline $\mathrm{R}_{3}(\mathrm{REEC})$ & 06 artigos \\
\hline $\mathrm{R}_{4}$ (EENCl) & 03 artigos \\
\hline
\end{tabular}

Fonte: Elaborado pelos autores.

Com base no quadro 7, notamos que a revista que apresenta uma maior quantidade de artigos nesta direção é a REEC. Principalmente, nos últimos anos, observamos esta elevação no número de artigos sobre o tema Natureza da Ciência.

No quadro 8, apresentamos a inserção de artigos sobre a temática nos diversos níveis de Ensino Fundamental (EF), Médio (EM), Superior (ES).

Quadro 8: Artigos por nível de ensino

\begin{tabular}{|c|c|}
\hline Nível de ensino & Quantidade de artigos \\
\hline EF (Ensino Fundamental) & zero \\
\hline EM (Ensino Médio) & 04 artigos \\
\hline ES (Ensino Superior) & 11 artigos \\
\hline
\end{tabular}

Fonte: Elaborado pelos autores

Por fim, no quadro 9, apresentamos uma análise da quantidade de artigos selecionados em relação aos critérios de inclusão.

Quadro 9: Artigos selecionados por critérios de inclusão

\begin{tabular}{|c|c|c|}
\hline Categoria & Trabalho & Total \\
\hline $\begin{array}{c}\text { Concepções de ciências alunos de } \\
\text { cursos superiores (TCES) }\end{array}$ & $01,02,03,04,11,13$ & 06 trabalhos \\
\hline $\begin{array}{c}\text { Concepções de ciências de alunos } \\
\text { da educação básica (TCEB) }\end{array}$ & 07,14 & 02 trabalhos \\
\hline $\begin{array}{c}\text { Reflexão didática sobre aspectos } \\
\text { da NdC (TRNDC) }\end{array}$ & 08,14 & 03 trabalhos \\
\hline $\begin{array}{c}\text { História da Ciência na educação } \\
\text { básica (THCEB) }\end{array}$ & $07,12,15$ & 04 trabalhos \\
\hline $\begin{array}{c}\text { História da Ciência no ensino } \\
\text { superior (THCES) }\end{array}$ & $01,02,09,13$ & 05 trabalhos \\
\hline Formação de professores (TFP) & $03,05,08,09,10$ & 02 trabalhos \\
\hline $\begin{array}{c}\text { Espaços não formais de ensino } \\
\text { (TEFN) }\end{array}$ & 06,12 & \\
\hline
\end{tabular}

Fonte: Elaborado pelos autores

Observamos, no quadro acima, que alguns dos trabalhos se encaixam em mais de uma categoria. Os dados apontam uma ampla discussão de aspectos da HFC e NdC em diferentes níveis e áreas de ensino como, por exemplo, educação básica (nível médio), ensino superior, formação de professores e espaços não formais. Isso ressalta a importância de se discutir tais aspectos no Ensino de Ciências, conforme discutem (ATAÍDE; SILVA, 2011; FORATO, 2009; SILVA, et al, 2014b). 
Neste momento, realizaremos uma análise qualitativa dos trabalhos, conforme descreve Gibbs (2009). Para tanto, centraremos nossa análise no: (a) nível de ensino, quantidade de participantes e duração; (b) conteúdo; (c) classificação do artigo, de acordo com o critério de inclusão; (d) objetivo do artigo; (e) como a NdC é utilizada em diferentes contextos de ensino; (f) as estratégias de ensino selecionadas e, para finalizar, (g) um breve desenho da proposta.

Artigo 1: Concepções epistemológicas de estudantes de Biologia e sua transformação por uma proposta explicita de ensino sobre historia.

a) Ensino Superior, 17 alunos e um semestre. b) História e Filosofia da Biologia. c) TCES, THCES. d) Abordar o conteúdo de História com ênfase sobre a História e Filosofia da Biologia e Filosofia da Ciência. e) Por meio de textos históricos e abordagem de questão filosófica. f) Atividades com discussão de textos lidos pelos alunos e exposições dialogadas. g) Trabalho qualitativo aplicado em uma turma da disciplina de História e Filosofia, com uso de questionário aberto e análise das coletas de dados.

Artigo 2: Concepções sobre a Natureza da Ciência num curso de biológicas: imagens que dificultam a Educação científica.

a) Ensino Superior, 31 alunos e um semestre. b) Biologia Molecular. c) TCES, THCES. d) Caracterizar as concepções da Natureza da Ciência presentes entre estudantes de Biologia. e) Por meio de investigação e discussões epistemológicas. f) Atividades com entrevistas semiestruturada e aplicação de questionário. g) Trabalho qualitativo com a elaboração e aplicação de um questionário e entrevista semiestruturada, a partir de situações problematizadas, com um roteiro básico de questões envolvendo conhecimentos de biologia molecular.

Artigo 3: Concepções sobre a Natureza da Ciência num curso de biológicas: imagens que dificultam a Educação científica.

a) Ensino Superior, 10 alunos e não especificado. b) $A$ interação entre museus e centros de ciência. c) TCES, TFP. d) Identificar através de análise dos experimentos contextos na exposição interativa dos centros e museus de ciências, as condições necessárias para a apreensão da cultura científica na concepção pós-positivista. e) Por meio de pesquisa, experimentos, observação e interpretação. f) Atividades de pesquisa onde foram realizadas visitas, debates e experimentos. g) Trabalho qualitativo participação dos envolvidos nas etapas do projeto, planejamento pesquisa, definição e do problema, discussão de hipóteses, escolha do referencial teórico e procedimentos de pesquisa coleta de dados e da análise de resultados.

\section{Artigo 4: Formulação de questões mediação da Leitura.}

a) Ensino Superior, 72 alunos e um semestre. b) Letramento científico. c) TCES. d) Ampliar as formas de mediação usadas por professores de Ciências em atividades de leitura em sala de aula. e) Levar para as aulas de ciências o investimento da leitura e produção de textos. f) Atividades de mediação de ensino. g) Trabalho qualitativo onde a experiência e produção de textos formulação de questionário diante dos resultados obtidos através da pesquisa.

Artigo 5: A Natureza da Ciência na formação de professores: reflexões a partir de um curso de licenciatura em ciência biológicas.

a) Ensino Superior, não especificado e não especificado. b) Revisão curricular. c) TFP. d) Observar alguns fundamentos teóricos que nos ajudem a interpretar o lugar desta discussão em um currículo compatível com a formação docente que desejamos construir. e) Por meio de textos históricos. f) Atividades com o uso de textos históricos, incluindo análise, debates e discussão. g) Trabalho qualitativo com análise de textos e reflexão a respeito da reformulação do currículo de professores. 
Artigo 6: Natureza da Ciência, relação entre a sociedade, ciência e tecnologia, crenças consensuais pesquisas empírica.

a) Ensino Superior, 16 alunos e não especificado. b) Ciência, Tecnologia e Sociedade. c) TEFN. d) Mostrar os consensos relativos às relações com a sociedade a ciência e a tecnologia. e) Por meio de uma pesquisa empírica com questões a respeito da NdC. f) Atividades avaliativa de questões sobre a $\mathrm{NdC}$, onde o principal instrumento empregado são as questões de opiniões sobre a ciência tecnologia e sociedade (CTS), todas tem como ponto inicial um pequeno texto. g) Trabalho de caráter avaliativo e qualitativo onde se estabeleceu os possíveis acordos sobre a $\mathrm{NdC}$ em recolher as avaliações de um painel de 16 juízes peritos com antecedentes profissionais diversificados mas todos voltados ao ensino de ciência para uma pesquisa direta de questões sobre a NdC.

Artigo 7: 0 diagnóstico de concepções sobre os cientistas através da análise e discussão de histórias de ficção regidas pelos alunos.

a) Ensino Médio, 3 alunos e não especificado. b) Ficção Científica. c) TCEB, THCEB. d) Diagnosticar concepções sobre o cientista e discutir as potencialidades desta metodologia na investigação e na educação científica. e) Por meio da construção de história de fiç̧ão científica analisando o papel do cientista e o próprio conhecimento do aluno e divulgação na mídia. f) Análise de três histórias de ficção científica, sobre o trabalho de um grupo de cientista, redigida por três alunos, e a realização de entrevista semiestruturada. g) Trabalho qualitativo baseado em estudo de caso, que envolve o impacto das questões sociocientíficas recente divulgadas pelos meios de comunicação nas concepções acerca da NdC de um grupo de alunos portugueses da disciplina de ciência, terra e vida.

Artigo 8: Os professores de Ciências Naturais e as discussões de controvérsias sócio científicas: dois casos distintos.

a) Ensino Superior, 2 alunos e um ano. b) Investigação e intervenção nos novos currículos de ciências. c) TRNDC, TFP. d) Compreender os fatores que condicionam a realização de atividade de discussão de questões sociocientifica controversas. e) Em atividades de discussão de questões sociocientifica e controvérsias. f) Aulas expositivas recolhidas informações através de entrevistas semiestruturadas, observação direta de sequências de aulas, análises de planos e matérias de ensinos produzidos pelos participantes. g) Trabalho qualitativo de dois estudos de casos com professoras de Biologia e Geologia do $11^{\circ}$ ano onde pretende compreender os fatores que influenciam a realização de atividades de discussão e questões sociocientifica.

Artigo 9: Aspectos sobre a Natureza da Ciência por alunos e professores de licenciatura em ciências biológicas.

a) Ensino Superior, 9 professores e 33 alunos e oito meses. b) Investigação sobre a história e epistemologia da ciência. c) THCES, TFP. d) Discutir o conceito de ciência e seu ensino, investigar conceitos de ciência de professores formadores e alunos de ciências biológicas, analisar o processo de construção conceitual da natureza do conhecimento científico ao Grupo de Pesquisas em Epistemologia da Biologia de Cascavel/PR/ Brasil - GEBCA. e) Por meio de questionário, observação e entrevista. f) Atividade de análise de dados e discussões gerais acerca da ciência, pesquisas e participação em grupos de debate. g) Trabalho qualitativo. A coleta de dados foi em três momentos distintos: aplicação de questionários a professores e alunos de um curso de ciências biológicas; observações de encontros do GEBCA; e entrevistas com alguns de seus membros.

Artigo 10: Clube de Ciências: o que pensam os professores sobre a Natureza da Ciência e Iniciação Cientifica. 
a) Ensino Superior, 7 professores e não especificado. b) Ciência Ensino de ciência e Natureza Ciência. c) TFP. d) Analisar as concepções de sete professores coordenadores de Ciências no município de Blumenau - SC sobre Ciência e NdC. e) Por meio de entrevista, iniciação científica e analise. f) Atividade usando a técnica de complemento identificando motivações, crenças e sentimento que dizem respeito ao objeto estudado. g) Trabalho qualitativo, de coletas de dados onde foi utilizado entrevista semiestruturados e a técnica de complementos, incluindo análise de resultados.

Artigo 11: Reflexões acerca das diferentes visões sobre a natureza da ciência e crenças de alunos de um curso de Ciências Biológicas.

a) Ensino Superior, 99 alunos e um semestre. b) Natureza da Ciência e crenças de estudantes de cursos superiores. c) TCES. d) Identificar as concepções sobre a NdC e as crenças que interverem na construção do conhecimento científico de estudantes de biologia. e) Por meio de discursos do sujeito coletivo através da HFC. f) Análise e discussão de questões fechadas e abertas referentes a características pessoais e visão de ciência. g) Trabalho de natureza quantitativo com análise das questões fechadas referentes a características gerais dos sujeitos e de quatro questões abertas referentes a visão de ciência para análise dos dados.

Artigo 12: Episódios da história da ciência em aulas de física com alunos jovens e adultos: uma Proposta didática articulada ao método de estudo de caso.

a) Ensino Médio, 8 alunos e treze semanas. b) Observações astronômicas do jesuíta Valentin Stanel no Brasil colonial. c) THCEB, TEFN. d) Contribuir para transforma a escola em um espaço de trabalho, pesquisa e formação em ciências de jovens e adultos. e) Por meio de episódios históricos, estudo de casos e História da Ciência. f) Utilizamos o método de estudo de caso, através de um ambiente virtual de ensino-aprendizagem, para trabalhar com episódios da história da ciência do Brasil colonial em uma turma de alunos da Educação de Jovens e Adultos em formação profissional. g) Trabalho qualitativo com o desenvolvimento das ações da proposta didática por meio de três subseções. Aborda o episódio histórico; as observações do jesuíta Valentin Stansel; trata do estudo de caso e a apresentação das ações de ensino praticadas em sala de aula e no EVA.

Artigo 13: Natureza da Ciência numa sequencia didática: Aristóteles, Galileu e o movimento relativo.

a) Ensino Superior, 16 alunos e oito horas. b) Movimento relativo. c) TCES, THCES. d) Identificar o conhecimento prévio do aluno sobre movimento relativo e aspecto da $\mathrm{NdC}$. e) Por meio de sequência didática usando atividades como leitura, elaboração de cartazes e encenação que envolveram tanto a parte conceitual quanto histórica. f) Atividades desenvolvidas nesta sequencia didática permitiram explorar alguns aspectos da natureza da ciência e também mostrar aos alunos que a Física possui mudanças de paradigmas. As discussões sobre as ideias de Aristóteles e Galileu sobre o movimento relativo. g) Trabalho qualitativo utilizando e recursos como o estudo de textos em grupos, a elaboração de cartazes e a encenação mostrando que a sequência didática elaborada para este trabalho pode servir de base para tratar de outros conceitos que possam ser associados a episódios históricos que geraram controvérsias.

Artigo 14: Natureza da luz e o ensino da óptica: Uma experiência didática envolvendo o uso da historia e da filosofia do ensino médio.

a) Ensino Médio, 78 alunos e dois meses. b) Óptica e Natureza da Ciência. c) TCEB, TRNDC. d) Identificar aspectos positivos e negativos no que diz respeito à compreensão de alguns conceitos da Óptica. e) Por meio de textos de História e Filosofia da Ciência. f) Atividades baseada na HFC, cuja estrutura contém etapas (atividades) que podem ser aplicadas a outros temas. g) Trabalho 
qualitativo, com o uso de pesquisa bibliográfica, elaboração de textos, atividade livre, utilização dos textos produzidos, aplicação do júri, atividade final.

Artigo 15: Reflexões sobre a Natureza da Ciência em aulas de física: estudo de um episódio histórico no Brasil colonial.

a) Ensino Médio, 8 alunos e dois meses. b) Brasil Colonial. c) THCEB. d) Introduzir a discussão histórica nas aulas de Física do público do PROEJA e debater sobre a produção da atividade científica, de modo a superar possíveis visões deformadas sobre a natureza da ciência, viabilizamos a articulação da história da ciência com o método de estudo de caso. e) Por meio de pesquisa, leituras, resenha defender ideias e desenvolvimento de habilidades e tecnologia computacional. f) Atividades envolvendo o método de estudo de caso aliado ao episódio histórico citado. g) Trabalho qualitativo concretizado em quatro etapas: planejar, agir, observar e avaliar. Com ciclos reflexivos, a pesquisaação. Estudo de caso em três partes: (i) contexto histórico; (ii) experimentos e ideias principais e (iii) implicações para a alfabetização científica e o ensino de ciências.

Podemos observar pelos dados acima que os conteúdos que trabalharam a $\mathrm{NdC}$ estão relacionados, principalmente, ao Ensino de Física, com destaque aos fatores históricos que contribuíram para estes trabalhos. Estes trabalhos, na sua maioria, são estudos de casos, que se utilizam de narrativas de indivíduos enfrentando, controvérsias, decisões ou dilemas para ensinar Física ou NdC.

Pode-se notar que a maioria dos artigos selecionados para esta análise retrata a NdC de forma integrada ao conteúdo de Historia e Filosofia da Ciência (HFC). Os artigos, em sua maioria, retratam a HFC como estratégia de ensino.

A formação de professores também tem grande destaque nos trabalhos que apresentam discussões sobre a NdC. Utilizando, principalmente, a História da Ciência, os pesquisadores buscam formas de ensinar aspectos da NdC para os professores ou em exercício ou formação.

Como já destacado, boa parte dos trabalhos encontrados são no Ensino Superior, totalizando 11 artigos. Além disso, encontramos 4 trabalhos direcionados para o Ensino Médio e nenhum encontrado no Ensino Fundamental. Tal resultado lança um sinal que propostas, como as apresentadas nos artigos, devem ser idealizadas, também, para o Ensino Fundamental.

Outro dado a ser destacado diz respeito ao tempo das intervenções didáticas. Não encontramos um padrão significativo nelas. Observamos que o tempo variava desde um ano até poucas horas. Não vamos problematizar sobre a questão tempo das intervenções, pois entendemos que cada uma delas apresentava seus pressupostos metodológicos e didáticos definidos.

Com relação aos desenhos metodológicos das pesquisas, podemos observar a predominância de trabalhos qualitativos, com ênfase para os questionários como instrumento de coleta.

\section{CONSIDERAÇÕES FINAIS}

As pesquisas incluídas no presente trabalho faz parte de um método de investigação chamado "Estado da Arte" de pesquisas. Para nosso estudo foram coletados os trabalhos publicados entre os anos de 2004 a 2013 das revistas supracitadas. 
Neste trabalho foram coletados 719 artigos em revistas brasileiras e estrangeira em Ensino de Ciência, os quais, após passarem pelos critérios de inclusão no estudo, apresentados no corpo do manuscrito, classificamos 15 trabalhos aptos para análise.

Esta investigação foi realizada com auxílio de quadros, possibilitando traçar uma síntese geral das publicações que utilizam esta temática. Com o propósito de analisar de forma mais criteriosa as informações encontradas, após a inclusão dos trabalhos foi feito uma leitura crítica de cada um deles, no sentido de classificá-los, conforme os critérios idealizados.

Os resultados da análise dos 15 trabalhos classificados permitiram observar quais as estratégias de ensinos são mais utilizados, suas metodologias, pressupostos teóricos e nível de ensino de aplicação. Conforme nossos resultados, notamos que a HFC é uma das principais formas de inserir a NdC na sala de aula, seja na formação dos professores ou no Ensino Médio.

Por fim, vale ressaltar, a escassez de intervenções didáticas no Ensino Fundamental, nos periódicos consultados. Este dado, em especial, chama-nos atenção e aponta, possivelmente, um caminho para futuras pesquisas.

\section{ARTIGOS ANALISADOS NA PESQUISA}

1. ALMEIDA, A. V.; FARIAS., C. R. O. A natureza da ciência na formação de professores: reflexões a partir de um curso de licenciatura em Ciências Biológicas. Investigações em ensino de ciências, v. 16, n. 3, p. 473-488, 2011.

2. CHINELLI, M. V.; AGUIAR, L. E. V. Experimentos e contextos nas exposições interativas dos centros e museus de Ciências. Investigações em Ensino de Ciências, v. 14, n. 3, p. 377-392, 2009.

3. EL-HANI, C. N.; TAVARES, E. J. M.; ROCHA, P. L. B. Concepções epistemológicas de estudantes de biologia e sua transformação por uma proposta explícita de ensino sobre história e filosofia das ciências. Investigações em Ensino de Ciências, v. 9, n. 3, p. 265-313, 2004.

4. HYGINO, C. B.; SOUZA, N. S.; LINHARES, M. P. Episódios da história da ciência em aulas de física com alunos jovens e adultos: uma proposta didática articulada ao método de estudo de caso. Revista Electrónica de Enseñanza de las Ciencias, v. 12, n. 1, p. 1-23, 2013.

5. Reflexões sobre a Natureza da Ciência em aulas de

Física: Estudo de um episódio histórico do Brasil colonial. Experiências em Ensino de Ciências, v. 7, n. 2, 2012.

6. LONGHI, A.; SCHROEDER, E. Clubes de ciências: o que pensam os professores coordenadores sobre ciência, natureza da ciência e iniciação científica numa rede municipal de ensino. Revista Electrónica de Enseñanza de las ciencias, v. 11, n. 3, p. 547-564, 2012.

7. OLEQUES, L. C.; BOER, N.; LADVOCAT, M. Reflexões acerca das diferentes visões sobre a natureza da ciência e crenças de alunos de um curso de Ciências Biológicas. Revista Electrónica de Enseñanza de las Ciencias, v. 12, n. 1, p. 110-125, 2013.

8. PAULA, H. F.; LIMA, M. E. C. C. Formulação de questões e mediação da leitura. Investigações em ensino de ciências, v. 15, n. 3, p. 429-461, 2010.

9. REIS, P.; GALVÃO C. O diagnóstico de concepções sobre os cientistas através da análise e discussão de histórias de ficção científica redigidas pelos alunos. Revista Electronica de 
Ensenãnza de lãs Ciências, v. 5, n.2, p.213-234, 2007.

10. .Os professores de Ciências Naturais e a discussão de controvérsias sociocientíficas: dois casos distintos. Revista Electrónica de Enseñanza de las Ciencias, v. 7, n.3, p.746-772, 2009.

11. SCHEID, N. M. J.; FERRARI, N.; DELIZOICOV, D. Concepções sobre a Natureza da Ciência num curso de Ciências Biológicas: Imagens que dificultam a educação científica. Investigações em Ensino de Ciências, v. 12, n. 2, p. 157-181, 2007.

12. SILVA, B. V. C.; MARTINS, A. F. P. A natureza da luz e o ensino da óptica: Uma experiência didática envolvendo o uso da História e da Filosofia da Ciência no ensino médio. Experiências em Ensino de Ciências, v. 5, n.2, p. 71-91, 2010.

13. SILVEIRA, A. F. et al. Natureza da Ciência numa sequência didática: Aristóteles, Galileu e o movimento relativo. Experiências em Ensino de Ciências, v. 5, n. 1, p. 57-66, 2010.

14. TOBALDINI, B. G. et al. Aspectos sobre a natureza da ciência apresentados por alunos e professores de licenciatura em ciências biológicas. REEC: Revista electrónica de enseñanza de las ciencias, v. 10, n. 3, p. 457-480, 2011.

15. VÁZQUES-ALONSO, A., et al. Consensos sobre a Natureza da Ciência: A Ciência e a Tecnologia na Sociedade. Química Nova na Escola, p.34-50, 2007.

\section{REFERÊNCIAS BIBLIOGRÁFICAS}

16. ACEVEDO, J. A. Enfoques explícitos versus implícitos en la enseñanza de la naturaleza de la ciência. Revista Eureka sobre Enseñanza y Divulgación de las Ciencias. v.6, n.3, p.355-386, 2009.

17. El estado actual de la naturaleza de la ciencia en la didáctica de las ciencias. Revista Eureka sobre Enseñanza y Divulgación de las Ciencias. v.5, n.2, p.134-169, 2008.

18. ACEVEDO, J. A., VÁZQUEZ, A., MANASSERO, M. A.; ACEVEDO, P. Consensos sobre la naturaleza de la ciencia: fundamentos de una investigación empírica. Revista Eureka sobre Enseñanza y Divulgación de las Ciencias. v.4, n.1, p.42-66, 2007 a.

19. Consensos sobre la naturaleza de la ciencia: aspectos epistemológicos. Revista Eureka sobre Enseñanza y Divulgación de las Ciencias. v.4, n.2, p.202-225, 2007b.

20. ATAÍDE, M. C. E. S.; SILVA, B. V. C. As metodologias de Ensino de Ciências: contribuições da experimentação e da História e Filosofia da Ciência. HOLOS, v. 4, p. 171-181, 2011.

21. BARDIN, L. Análise de conteúdo. Lisboa: Edições 70, 2009.

22. BRICCIA, V.; CARVALHO, A. M. P. Visões sobre a natureza da ciência construídas a partir do uso de um texto histórico na escola média. Revista Eletrónica de Eseñanza de las Ciencias. v.10, n.1, p.1-22, 2011.

23. CARVALHO, H. R. A utilização de textos históricos de natureza pedagógica para discussão de aspectos relacionados à natureza da ciência: uma proposta metodológica. Trabalho de Conclusão de Curso. Universidade Federal do Piauí. 2015.

24. FERREIRA, J. M. H.; MARTINS, A. F. P. Avaliando a inserção da temática natureza da ciência na disciplina de história e filosofia da ciência para graduandos em física na UFRN. In: PEDUZZI, L. 
O. Q.; FERREIRA, J. M. H.; MARTINS, A. F. P. (Org.). Temas de História e Filosofia da Ciência no Ensino. Natal: EDUFRN, 2012.

25. FORATO, T. C. M. A natureza da ciência como saber escolar: um estudo de caso a partir da história da luz. Tese de Doutorado. Universidade de São Paulo. 2009.

26. GIBBS, G. Análise de dados qualitativos. Porto Alegre: Artmed Editora, 2009.

27. HARRES, J. B. S. Uma revisão de pesquisas nas concepções de professores sobre a natureza da ciência e suas implicações para o ensino. Investigações em Ensino de Ciências, v. 4, n. 3, p. 197-211, 1999.

28. LEDERMAN, N. G. Nature of Science: past, present and future. In: Abell, S.K (Org); Lederman, N.G (Org). Handbook of research of Science Education. Mahwal: Lawrence Erlball Associates, p.881-880, 2007.

29. Teacher's Understanding of the Nature of Science and Classroom Practice: Factors That Facilitate or Impede th Relationship. Journal of Research in Science Teaching. v.36, n.8, p.916-929, 1999.

30. MARCONI, M. A. Fundamentos de metodologia científica. São Paulo: Atlas, 2003.

31. MOREIRA, M. A. Metodologias de Pesquisa em Ensino. São Paulo: Editora Livraria da Física, 2011.

32. MOURA, B. A. A aceitação da óptica newtoniana no século XVIII: subsídios para discutir a Natureza da Ciência do Ensino. Dissertação de Mestrado. Universidade de São Paulo. 2008.

33. PAGLIARINI, C. R. Uma análise da história e filosofia da ciência presente em livros didáticos de física para o ensino médio. 2007. 115f. Dissertação (Mestrado em Ciências) - Universidade de São Paulo, São Carlos, 2007.

34. SILVA, B. V. C. A natureza da ciência pelos alunos do ensino médio: um estudo exploratório. Latin American Journal of Physics Education, v.4, n.3, p. 670-677, 2010.

35. A história e filosofia da ciência na formação dos professores: um estudo no curso de física da UFPI. Revista Ciências \& Idéias, v. 1, p. 39-50, 2014a.

36. et al. As necessidades formativas do professor de ciências ao inserir a História e a Filosofia da Ciência na sala de aula: o uso dos textos históricos de natureza pedagógica. Ensino de Ciências e Tecnologia em Revista, v. 4, p. 31-45, 2014b.

37. TEIXEIRA, E. S.; GRECA, I; FREIRE JR., O. Uma Revisão Sistemática das Pesquisas Publicada no Brasil sobre o Uso Didático de História e Filosofia da Ciência no Ensino de Física. In: Peduzzi, L. O. Q.; Martins, A. F. P.; Ferreira, J. M. H.. (Org.). Temas de História e Filosofia da Ciência no Ensino. 1ed. Natal: EDUFRN, v. 1, p. 9-40, 2012. 